\title{
Using dialogue to contextualize culture, ecosystem services, and cultural ecosystem services
}

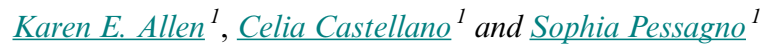

\begin{abstract}
We propose an alternative methodology for engaging with multifaceted cultural ecosystem services (CES) in the Global South. We explore the use of dialogue as a tool for understanding CES in situ, while developing shared action steps toward CES conservation among stakeholders. We held six dialogue workshops in the rural Central Pacific region of Costa Rica that were designed to foster understanding of shared community values for ecosystem services and associated conservation challenges. In two of the workshops, we employed model-based reasoning through which we used maps as boundary negotiating objects to nurture dialogue on CES values, observations, and concerns. In four of the workshops, we used photovoice to elicit reflection and dialogue on CES values and changes in ecosystem services in the region. Observations and surveys of workshop participants revealed that the process engendered reflection on ecosystem service values, and community support and enthusiasm for future communal efforts. These workshops demonstrated how dialogue can elucidate local values for CES, while strengthening support across stakeholders for improved conservation actions. We propose that this methodology is applicable in various contexts for improved CES assessment across diverse stakeholders.
\end{abstract}

Key Words: community engaged research; cultural ecosystem services; dialogue; photovoice

\section{INTRODUCTION}

Recent literature has increasingly called for recognition that the values of ecosystem services are relational, context-dependent, and culturally constructed (Chan et al. 2016, Klain et al. 2017, Pascual et al. 2017). This recognition incorporates the perspective of anthropologists and other social scientists on the role of culture in shaping human value systems (Graeber 2001) — value systems which in turn determine ecosystem services values. This stands in contrast to the perspective that ecosystem services are reducible to a simplistic monetary exchange value for better incorporation into policy (Boyd and Banzhaf 2007). Early ecosystem services literature appeared hopeful - if we could accurately estimate the value of ecosystem services, they might better convince policymakers of the value of nature (Costanza et al. 1997, Daily et al. 1997). Studies quickly revealed the challenges of this endeavor. For one, it is difficult to reduce ecosystem services to fungible units of trade (Norton and Noonan 2007, Wegner and Pascual 2011). Further, following economic logic, the public will place value on final ecosystem services, but the intermediate services might be those most critical to protect (Fisher et al. 2009). And finally, the question quickly arose-Whose value counts (and what type of value counts) (Chan et al. 2012a, Small et al. 2017)?

Consideration of cultural ecosystem services (CES) as the "nonmaterial benefits (e.g., experiences, capabilities) that people derive from human-ecological relations" (Chan et al. 2011: 206) further complicates our understanding of ecosystem services values. Cultural ecosystem services are not merely created by the interworking of abiotic and biotic factors in a particular place; they are also created through the interplay of diverse cultures with particular local environs (Chan et al. 2012b). Hence, CES are, by definition, context dependent. Anthropologists have long asserted that values are not absolute; they are embedded within cultures and can only be fully understood in context (Polanyi 1957, Dalton 1961, Munn 1986, Graeber 2001). Furthermore, political ecologists and environmental historians have documented that the nature-culture divide that shapes our environmental discourse is derived from a western worldview (Cronon 1995, West et al. 2006), one that sees nature as something to either be conserved or exploited (Koppes 1988, Adams 2004). Other scholars have pointed out that this mindset directly stems from capitalism, a system promoting that we value commodities as fungible units (Kosoy and Corbera 2010). These scholars have argued that the framing of environmental values under "ecosystem services" ignores this historical and social complexity, and runs the risk of erasing the role of culture in shaping how humans interact with and value ecosystems (McAfee and Shapiro 2010, Matulis 2014). Hence, devising a framework for understanding and valuing CES for better incorporation into policy is a formidable challenge.

Numerous studies have relied on valuation techniques, or the estimation of monetary value ascribed to goods, services, and commodities, for ecosystem services assessment and landscape planning (Polasky et al. 2008, Nelson et al. 2009, de Groot et al. 2010, Cavender-Bares et al. 2015). The need for a uniform understanding of values to facilitate incorporation of CES into regional, national, and global policies has resulted in the promotion of these economic valuation methodologies, which largely abstract CES from context in order to estimate a simplified, translatable, monetary value (Daily et al. 2009, Jax et al. 2013, Cavender-Bares et al. 2015). However, scholars have repeatedly demonstrated that CES represent dynamic humanenvironment interactions; hence, overlaying a cost-benefit analysis or utilitarian valuation framing on CES might obscure the intangible benefits of the landscape and the contextdependent nature of culture (Daniel et al. 2012, Tengberg et al. 2012). Furthermore, the economic valuation of CES might be particularly problematic when employed in the Global South, as valuation methods have been developed predominantly using experiments and case studies from the Global North (Hanley et al. 2001, Champ et al. 2003, Polasky et al. 2008). More holistic CES assessment methods are therefore necessary, particularly in 
the Global South, to identify the role CES play in the lives of communities, while improving the incorporation of CES into environmental planning.

Deliberation provides an alternative methodology that offers the possibility of characterizing multidimensional CES values to inform environmental decision-making. These approaches use discussion and deliberation to encourage public participation and reflection, and they have been employed across a spectrum of methods ranging from efforts to improve monetary valuation to methods that reject economic framing of ecosystem services values (Bunse et al. 2015). However, there is discord across this literature in terms of the purpose of deliberation. Some studies have shown that deliberation can result in improved monetary estimates of ecosystem services (Lienhoop and Völker 2016, Mavrommati et al. 2017). Other studies emphasize that the role of deliberation lies primarily in promoting stakeholder engagement and fostering positive conservation measures (Proctor and Dreschler 2006, Gregory et al. 2012, Partelow et al. 2019). There appears to be a tension across these approaches, as the very goals of deliberation and value elicitation seem to influence the process itself, and therefore the outcomes (Satterfield 2001, Kenter et al. 2011). We build on deliberative methodologies by testing two different methods, both designed to foster dialogue across stakeholders and increase understanding of CES.

We explore specifically the use of dialogue in deliberation, hypothesizing that methods that promote dialogue across stakeholders can aid in the development of shared action steps while increasing researcher understanding of CES values in situ. We begin by briefly reviewing the techniques we used to elicit dialogue, and the role of dialogue in conservation discourse. We then describe a series of workshops held in the rural Central Pacific region of Costa Rica that we designed to initiate dialogue about shared community values for ecosystem services and associated conservation challenges. These workshops demonstrate how dialogue can elucidate local values for CES while strengthening support across stakeholders for improved conservation actions. We then discuss how this methodology reveals the tension between CES value elicitation (characterized as extractive measures) and stakeholder engagement, and the lessons learned for improved CES assessment across diverse stakeholders.

\section{BACKGROUND}

\section{Dialogue}

Dialogue has received significant attention in myriad academic and applied circles as a means of bridging diverse stakeholders, particularly in circumstances where lines of communication have broken down (Bohm and Nichol 1996, Stammler and Peskov 2008, Gurin et al. 2013). The goal of dialogue, written by one of the foundational theorists, is worth quoting at length:

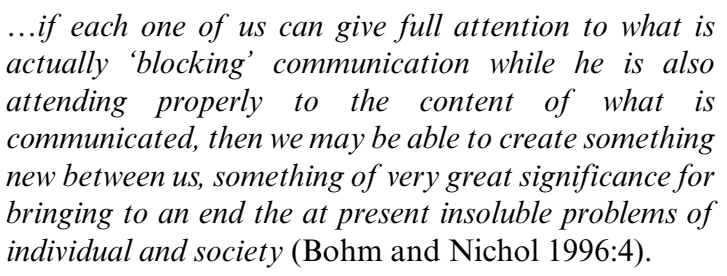

Conceptually, dialogue offers the possibility of facilitating authentic stakeholder engagement in critical issues of mutual concern. Dialogue, then, can be used to bridge differences and foster connections. It has been used in situations such as facilitating engagement across different groups on college campuses (Zúñiga 2003), and bridging stakeholders and policymakers in watershed management (Falkenmark et al. 2004).

Though the word "dialogue" is sometimes used haphazardly, scholars have developed goals and processes that distinguish dialogue from other forms of communication. The key ingredient is to open lines of communication: "...to listen to everybody's opinions, to suspend them, and to see what that means. If we can see what all of our opinions mean, then we are sharing a common content..." (Bohm and Nichol 1996:26). Scholars contrast dialogue with other words that might describe conversation, such as "discussion" and "debate" (Dessel and Rogge 2008). Dialogue is a particular form of communication whose goal is to develop a shared understanding of the topic at hand through the process of careful listening, lowering defenses, and critical self-reflection (Schatz et al. 2003). Dialogue, then, stands as a particular kind of communication that allows participants to develop a shared meaning of the experience.

In social-ecological research, there are multiple potential methods of fostering dialogue. For example, focus groups can be used to understand stakeholder perceptions through dialogue, but often this methodology is targeted and more extractive because it focuses more on value elicitation and less on dialogue for fostering connection (Marková et al. 2007). Deliberative processes, such as structured decision-making and deliberative valuation, may nurture conversation across stakeholders, but dialogue itself is not always an expressed goal (Howarth and Wilson 2006, Gregory et al. 2012). Participatory mapping also describes discussion and conversation as critical to the methodology (Palomo et al. 2014, Kenter 2016). These methods all involve bringing together diverse stakeholders to discuss scenarios and local challenges, processes that can cultivate "dialogue." However, dialogue as a process in and of itself emphasizes the quality of communication as a central objective rather than a means to an end. In this regard, dialogue is a potentially powerful engaged methodology for arriving at a common understanding and reconciling conflict, in this case conservation conflict, as opposed to an improved methodology for extracting information to subsequently incorporate into policy.

In our research, we chose model-based reasoning through boundary negotiating objects, and photovoice, as the particular methods used to engage stakeholders in dialogue. We describe these methods, and in the Discussion, reflect on their usefulness as tools for (1) understanding CES values, and (2) fostering stakeholder engagement and reconciling conservation conflicts. We further identify potential trade-offs between these goals in terms of methodological design.

\section{Model-based reasoning}

Our research borrows from a distinct application of model-based reasoning developed by the EMBeRS (Employing Model-Based Reasoning in Socio-Environmental Synthesis) project, funded by the National Socio-Environmental Synthesis Center (Pennington et al. 2016). Pennington et al. (2016) describe a process of employing boundary negotiating objects to generate shared 
knowledge across individuals in interdisciplinary and transdisciplinary socio-environmental teams. Model-based reasoning is a cognitive process through which people build internal mental models of situations as a key step in reasoning so that they can process, understand, and negotiate information and concepts (Nersessian 1999). Boundary objects are shared concepts, artifacts, and spaces that are generated through different groups coming together on a common task, and are critical to providing a common focal point (Star and Griesemer 1989). In turn, boundary negotiating objects have been defined as, quite literally, boundary objects that are fluid in nature, as their meaning is created and negotiated across actors (Lee 2007). The EMBeRS project synthesized the concepts of boundary negotiating objects with model-based reasoning to describe the process by which workshop participants can use external objects to explore, adjust, and reshape individual mental models as they engage with each other in a group setting, and to potentially lead to the development of a shared understanding and meaning. The boundary negotiating object allows individuals to test and reshape their individual mental models, and approximate a shared understanding. We borrowed the process of model-based reasoning with boundary negotiating objects (MBR) to initiate dialogue, while subsequently providing a space for individuals to conceptualize preconceived mental models about the socialecological challenges in their communities.

\section{Photovoice}

Photovoice is a photographic technique, similar to MBR in nature, that uses photographs rather than written words and survey statistics as a subject of analysis (Wang and Burris 1997, Harper 2002, Carlson et al. 2006). Wang and Burris (1997) developed this method from the idea of critical consciousness, personal experiences, and documentary photography. The three goals of photovoice are to (1) enable people to record and reflect on their community's strengths and concerns, (2) promote critical dialogue about important issues through large and small group discussion of photographs, and (3) communicate to policymakers (Wang and Burris 1997). Photovoice then walks the line between MBR, as primarily process oriented, and other value elicitation methods. In photovoice, the researcher typically provides participants with a prompt, which they "answer" with photographs. Subsequently, participants gather to share photographs and converse about the meaning of the images they captured. Photovoice enhances exploration of subject matter by allowing participants to go into their environment and take photographs, thereby spurring deeper and longer engagement in the topic (Wang and Burris 1997). As a method of value elicitation that contrasts with surveys, photovoice gives participants the chance to speak freely about their values without predetermined choices. It also lifts people past the written word and makes it accessible to those with limited written language skills.

Photovoice methods can be particularly insightful in environmental research. Numerous studies have employed this methodology on topics ranging from environmental degradation and human health risks in Indigenous communities in Canada (Castleden et al. 2008, Healey et al. 2011) to community water values and environmental management in Australia (Maclean and Cullen 2009), and social and environmental changes in coastal communities on the Andaman Coast of Thailand (Bennett and Dearden 2013). One study analyzed the intersection between ecological and social systems in the Volcán River watershed area of Costa Rica and found that photovoice can complement other value elicitation methodologies (Berbés-Blázquez 2012). Moreover, photovoice can be used to increase stakeholder engagement in environmental issues by fostering dialogue along with a sense of ownership and autonomy (Castleden et al. 2008). It may also strengthen partnerships between conservation organizations and community members (Wang and Burris 1997).

We compare MBR and photovoice as methods that can both elicit CES values and engage participants in critical dialogue about environmental issues. Our approach allows us to understand the trade-offs inherent in understanding CES across process-oriented stakeholder engagement approaches and value elicitation methods.

\section{METHODS}

This research was part of a larger community-engaged conservation project developed to understand and support the scaling up of local conservation goals to meet landscape conservation imperatives, and was not specifically designed to assess CES values. The lead author has more than 10 years of engaged research experience in the region, which facilitated trust with stakeholders and engendered support and enthusiasm for the processes used. Collectively, we combined participant observation, dialogue workshops (MBR and photovoice workshops), semi-structured interviews, and post-workshop surveys in the broader community-engaged process. We specifically focus on the results and perceived impacts of the dialogue workshops, but we feel it is critical to emphasize the role of long-term commitment and engagement with process in the potential success of this approach, as mutual respect and trust across stakeholders was a critical contributor to the outcomes we observed.

We held dialogue workshops in two different communities: Costa de Pájaros, a coastal fishing community of approximately 5000 people on the Gulf of Nicoya, and Santa Rosa, a rural mountainous farming community of approximately 200 people located $25 \mathrm{~km}$ northwest of Costa de Pájaros (Fig. 1). We selected these two communities because they represent diverse ecosystems and livelihoods, and yet they are united by regional conservation efforts that encompass both locations. The engaged nature of our research informed its design - we compared the ability of two different styles of dialogue workshops, MBR and photovoice, in terms of the ability to foster stakeholder engagement, facilitate dialogue about conservation challenges, and elicit CES values. The MBR workshops were designed to emphasize process, dialogue, and engagement, and attempted to engender as inclusive participation as possible. The photovoice workshops emphasized dialogue and value elicitation, and involved a much smaller subset of the population. All research was conducted under Institutional Review Board approval FU052218. All workshops were held in Spanish, and the authors translated codes, key quotes, and terminology into English in the Results section.

\section{Photovoice workshops}

We used snowball sampling to recruit adult photovoice participants by asking key collaborators to recommend people who might be interested in the workshops. We partnered with the local elementary school in each location, and the school invited 
the minor participants. We held two photovoice workshops in each community - one with adults and one with minors - to test the method across age ranges. We attempted to gain equal gender representation in each group. The target number of participants for each photovoice workshop was five, but because we did not want to exclude anyone from the experience (particularly children who were eager to participate), total numbers of participants varied across each group (Table 1). We recognize that this did not result in an inclusive sample but rather a small convenience sample. Since the purpose of this design was to understand the methods as a means of dialogue, engagement, and value elicitation as opposed to understanding CES more broadly across the population, we do not believe that this limited sample hindered our results or conclusions.

Fig. 1. Study sites in the Central Pacific region of Costa Rica. National Geographic Basemap credits: National Geographic, Esri, Garmin, HERE, UNEP-WCMC, USGS, NASA, ESA, METI, NRCAN, GEBCO, NOAA, increment P Corp.

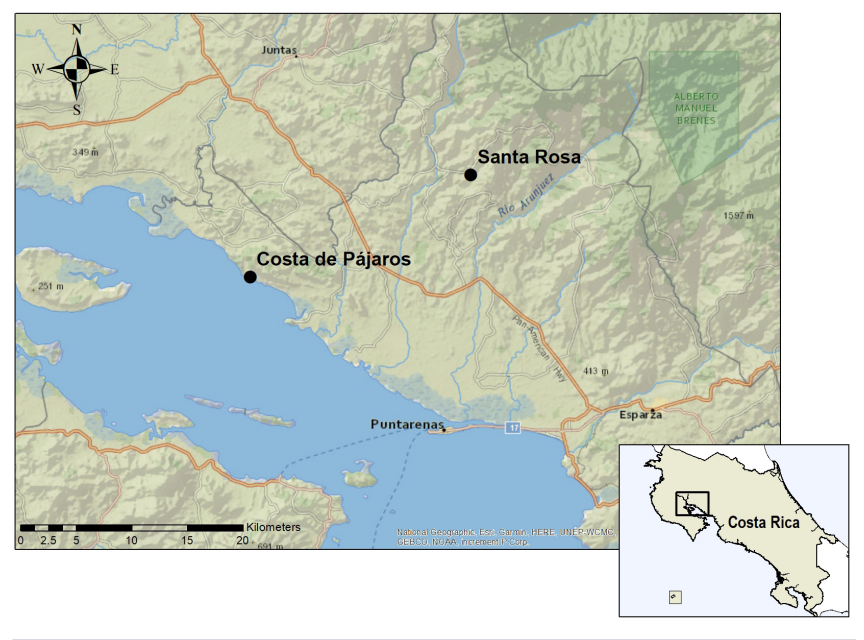

Table 1. Demographic characteristics of photovoice workshop participants.

\begin{tabular}{lcc}
\hline \hline Demographics & Costa de Pájaros & Santa Rosa \\
\hline Age & 5 & 6 \\
15 and under & 3 & 6 \\
37 and over & & \\
Sex & 4 & 6 \\
Male & 4 & 6 \\
Female & 8 & 12 \\
Total number of participants &
\end{tabular}

We held two multi-day photovoice workshops in each community: one with adults and one with minors. All participants attended both days. We separated participants into groups based on their age so they would feel comfortable sharing photographs with each other. We adapted stages of the photovoice process from Wang and Burris (1997), Castleden et al. (2008), Berbés-Blázquez (2012), Bennett and Dearden (2013), and Mattouk and Talhouk (2017). The photovoice sessions began with 30-minute training workshops to orient participants. During this time, we described the photovoice process and the objectives of our study, requested consent, and explained how to use the cameras. Three adult participants from Costa de Pájaros used their cell phone cameras instead of the digital ones to show important photos they had taken prior to the study. At the end of the training workshops, we gave participants three prompts to elucidate environmental values, conservation actions, and perceived changes (Table 2). We then gave participants 1 to 2 days, depending on their availability, to bring in 15 photos per prompt for the next workshop. At the following workshop, we asked participants to identify their five "best" photos per prompt to share with the group. During the presentation of each participant's photographs, participants commented on each other's photos, which resulted in a dialogue. After the presentations, participants individually narrowed down their photos to the final three favorite photos, and wrote a title and short description of the photos on a worksheet. We recorded and transcribed the dialogues from the second photovoice workshop, and analyzed the photographs and dialogues for the themes using MAXQDA 11.0.

Table 2. Prompts given to participants for photovoice workshops.

\begin{tabular}{ll}
\hline \hline Prompt & Target concept \\
\hline When or where do you feel most connected to the & Environmental \\
environment? & values \\
What do you do in your daily life to help conserve & Conservation \\
the environment? & actions \\
How has the environment changed in the last 5 & Perceived \\
years? & environmental \\
& changes \\
\hline
\end{tabular}

We identified themes by using grounded theory, allowing the themes to arise from the text and photographs (Ryan and Bernard 2000, 2003). We categorized some of the themes according to ecosystem services, as described in the Millennium Ecosystem Assessment (2003) (Table 3). We analyzed frequency by counting the number of times photographs and accompanying descriptions highlighted a theme. In order to summarize the most commonly perceived changes, we created graphs of the themes that had a minimum of two mentions.

\section{Model-based reasoning workshops}

We designed these workshops to engage stakeholders in conservation dialogues, and as such paid less attention to concepts such as sample size and representation, and emphasized inclusivity of stakeholders and relevance of topics to community needs. Because of this, the methods and workshop design were more organic and place-based as opposed to typical research methods. This resulted in particular strengths and weaknesses, which we address in the Discussion.

We invited stakeholders in accordance with the goals and expectations of community partners. In Costa de Pájaros, we focused on inviting representatives from various community organizations. These included members of women's organizations from Costa de Pájaros and the neighboring community of Manzanillo, local fishing organizations, and community leaders in sustainable agriculture. Collectively, 30 adults attended the workshop in Costa de Pájaros. Santa Rosa is a smaller town, so we attempted to invite every family and encouraged inclusive participation. We went door-to-door and distributed fliers to 
approximately 50 households. We had a resulting participation of 35 adults in the Santa Rosa workshop, and numerous children were in attendance, though they did not tend to participate in many of the activities.

Table 3. Environmental values identified from photovoice workshops (prompt 1). The ecosystem service categories are derived from the Millenium Ecosystem Assessment (2003).

\begin{tabular}{|c|c|c|}
\hline Code & Key words, concepts expressed & $\begin{array}{l}\text { Ecosystem } \\
\text { service category }\end{array}$ \\
\hline Tourism & $\begin{array}{l}\text { Tourists, visitors } \\
\text { "Scenery for the tourists." }\end{array}$ & Cultural \\
\hline Sustenance & $\begin{array}{l}\text { Providing food for consumption, water, } \\
\text { shelter, oxygen, medicinal properties } \\
\text { "We climb the trees, and they give me } \\
\text { fruit." }\end{array}$ & Provisioning \\
\hline Recreation & $\begin{array}{l}\text { Enjoying spending time in nature } \\
\text { "At the waterfall on our farm, we enjoy } \\
\text { the environment." }\end{array}$ & Cultural \\
\hline Familial & $\begin{array}{l}\text { Family, friends, human relationships } \\
\text { "I like to plant with my grandmother." }\end{array}$ & Cultural \\
\hline Economic & $\begin{array}{l}\text { Money, work, or the economy } \\
\text { "There are good changes that give me } \\
\text { profits." }\end{array}$ & $\begin{array}{l}\text { Cultural/ } \\
\text { provisioning }\end{array}$ \\
\hline Conservation & $\begin{array}{l}\text { Stewardship, conservation, environmental } \\
\text { education } \\
\text { "By planting trees, we help conserve the } \\
\text { environment." }\end{array}$ & Cultural \\
\hline Biodiversity & $\begin{array}{l}\text { Plant and animal diversity } \\
\text { "It is a vine that produces very rich } \\
\text { fruits... and the monkeys like them." }\end{array}$ & N/A \\
\hline Aesthetic & $\begin{array}{l}\text { Use of terms referring to views or } \\
\text { landscape features } \\
\text { "I like the landscape, to observe the birds } \\
\text { and their colors." }\end{array}$ & Cultural \\
\hline
\end{tabular}

Numerous studies have used participatory mapping to elicit ecosystem services values across stakeholders (Klain and Chan 2012, Darvill and Lindo 2015, Paudyal et al. 2015). These studies typically use maps as a means of involving local communities in the process of proscribing meaning on the landscape or extracting spatial information about human-environment relationships (Brown and Fagerholm 2015). As an alternative use of mapping and spatial visualization, we employed maps as boundary negotiating objects (Lee 2007, Pennington et al. 2016) through which participants could express and negotiate their understanding of the landscape and their relationship to environmental features. Participants were not asked to identify particular features on the landscape but rather used the maps to explore and discuss the surrounding areas.

In each workshop, we asked participants to divide into groups of five to eight individuals. We provided the groups with two laminated maps, dry erase markers, Post-it notes, and pens. One of the maps was a zoomed-in Google Earth image of the town, with the town center labeled and major roads identified. The other map was a zoomed-out image of the Bellbird Biological Corridor, the conservation planning region encompassing both towns (SINAC 2009). We gave participants limited prompting, and suggested only that they use the maps to discuss the state of the environment in their communities and the region. We indicated that they might use the dry erase markers and Post-it notes to identify general environmental concerns and potential solutions as represented by, reflected in, or invisible in, the maps. After approximately 30 minutes of small group dialogue, we brought all participants together and shared perspectives on the maps. We asked each group to summarize their main points of discussion, using the maps when appropriate to illustrate their understanding of local environmental challenges and potential solutions. As facilitators of this process, we made notes on boards of the presentations and facilitated group dialogue on points of concern or shared visioning of solutions.

We audio recorded the workshop components with permission from the participants, including small group discussions and final sharing and debriefing. We used these audio recordings to understand the process of dialogue, record key quotes, and confirm field notes and observations. Because we wanted to optimize the comfort level of the participants, the recorders were placed on group tables in an out-of-the-way location, which resulted in poor audio quality. This made complete transcription of the dialogue impossible but was in keeping with the organic, participant-centered nature of the workshops.

To assess the quality of the experience of participants in the workshops, we created an exit survey. We attempted to include all workshop participants in the survey. The exit surveys had questions about previous connections to conservation organizations, and participant experiences in the workshops (Table 4). We had a response rate of $52 \%$. This lower response rate was likely because some participants had to leave early from each meeting. Also, there was a heavy downpour during the Santa Rosa meeting, which caused a bit of chaos at the conclusion and prevented every participant from being surveyed.

Table 4. Exit survey questions for dialogue workshops.

\section{Questions}

1. Have you had contact with conservationists or conservation organizations before today's workshop?

2. After participating in today's workshop, do you feel optimistic about the possibility of collaborating in sustainability projects in the area? To represent your answer accurately, choose 1 to 10: 1 means "never," 5 means "neutral feeling," and 10 means "yes, absolutely."

3. Would you be willing to attend another workshop similar to today's workshop? Why or why not?

4. After today's workshop, do you feel enthusiastic about applying sustainable methods? To represent your answer accurately, choose 1 to 10: 1 means "I'm not excited," 10 means "I'm very excited."

\section{RESULTS}

\section{Photovoice workshops}

Overall, 20 people participated in the photovoice project: $60 \%$ were from Santa Rosa, 40\% were from Costa de Pájaros (Table 1). We attempted to get even participation from both minors and adults, as well as from Santa Rosa and Costa de Pájaros. However, due to a lack of time, fewer adults than minors participated, and in Costa de Pájaros, we had fewer total participants.

\section{Ecosystem service values and stewardship}

The first prompt from the photovoice workshops elicited 
environmental values, which overlapped with CES and relational values (Table 3, Fig. 2). In order of frequency, both communities valued aesthetics, biodiversity, recreation, conservation, sustenance, and family (Fig. 3). Most of these values fall into the category of CES, according to the Millennium Ecosystem Assessment (2003). Note that the top values in both locations related to the participants' rediscovering of the sense of place and their homes, concepts that can be categorized as CES but which also fit the new conceptualization of nature's contributions to people and relational values by the Intergovernmental SciencePolicy Platform on Biodiversity and Ecosystem Services (IPBES) (Fig. 3) (Pascual et al. 2014, Díaz et al. 2015).

Fig. 2. Photographic examples of top six values expressed among all participants. Quotations reflect emic descriptions of the value of the photo. Tourism and economic values are not shown because they were expressed by only one community.

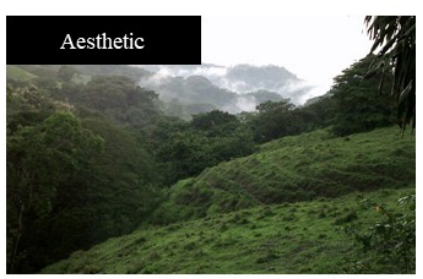

"After the rain, it is very pretty, as you can see the mist in the mountains."

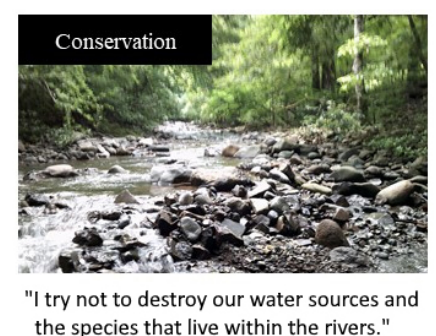

"I like to play in the plaza." the species that live within the rivers."

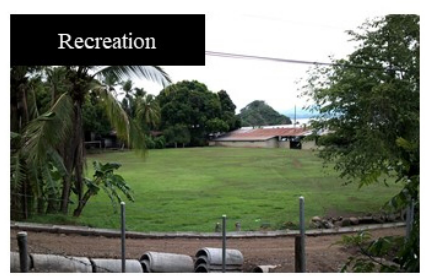

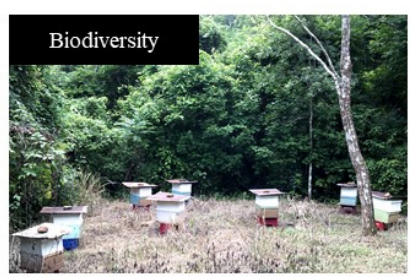

"Bees are very important for pollination."

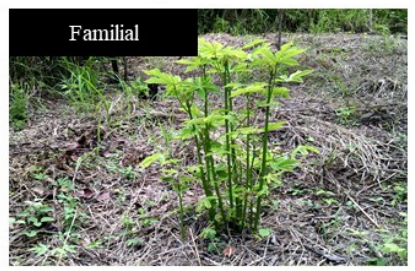

"I like to plant with my grandfather."

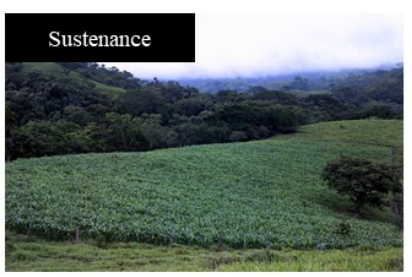

"Growing food."
In terms of the second prompt, "What do you do in your daily life to help conserve the environment," both communities expressed the same top four values with the same descending order of frequency: planting, farming, fostering animal diversity, and reforestation (Table 5, Fig. 4). However, participants from Costa de Pájaros mentioned cleanup, controlling natural disasters, and education more frequently than did those from Santa Rosa, while participants from Santa Rosa mentioned composting, building infrastructure, recycling, protection, and alternative transportation more frequently.
Fig. 3. Code breakdown of photographic responses to the question, "When or where do you feel most connected to the environment?" Frequency refers to the number of times a code was raised by different members of the community.

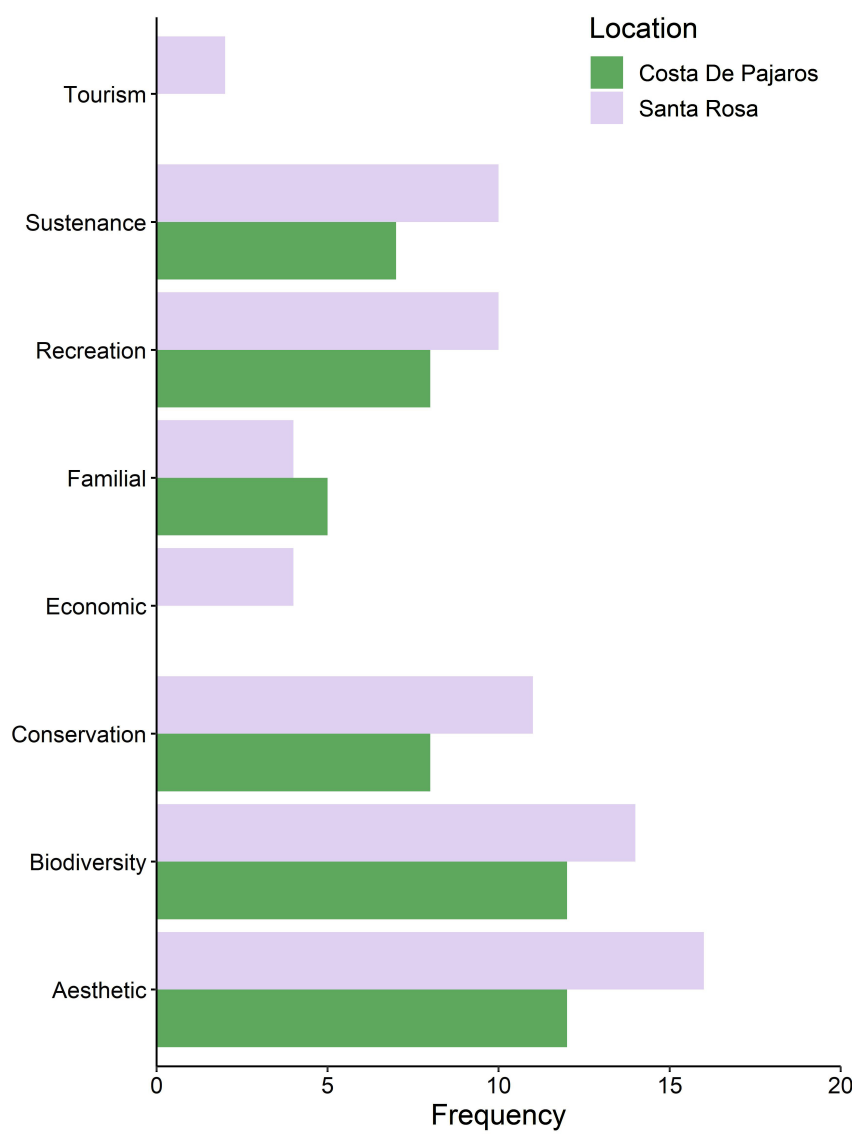

Conversation and dialogue regarding photographs provided depth and context for environmental values and actions. For example, one adult community member in Costa de Pájaros described how a few months earlier a fire had spread through the forested mountains near his house. He explained how he respects the trees and the land he lives on, so he wanted to do something to help. He and his friends hiked up the mountains and helped extinguish the fire. After the fire had subsided, he and his friends planted Guanacaste trees along the mountain to help reforest the land. He took photos of himself working to fight the fire and restore the natural environment, though we did not include them here to preserve his anonymity. The children of Costa de Pájaros also mentioned the devastating forest fire that took out a number of trees on the surrounding mountains. Although they were not sure if the fire was accidental or intentional, many community members agreed that the weather seemed to be getting hotter and drier recently, and potentially is exacerbating the fire. 
Table 5. Codes for conservation actions (prompt 2).

\begin{tabular}{|c|c|}
\hline Code & Key words, concepts expressed \\
\hline Reforestation & $\begin{array}{l}\text { Planting trees for reforesting the land } \\
\text { "By planting these trees, we help the environment." }\end{array}$ \\
\hline Recycling & $\begin{array}{l}\text { Re-using and recycling materials } \\
\text { "We recycle the containers we don't need instead of } \\
\text { throwing them away." }\end{array}$ \\
\hline Protection & $\begin{array}{l}\text { Protecting, caring for, helping the environment } \\
\text { "We try to protect our watershed and the species that } \\
\text { live in the rivers." }\end{array}$ \\
\hline Planting & $\begin{array}{l}\text { Planting for recreation, including gardening } \\
\text { "I planted this orchid on a piece of wood and tied it } \\
\text { to the tree." }\end{array}$ \\
\hline $\begin{array}{l}\text { Fostering animal } \\
\text { diversity }\end{array}$ & $\begin{array}{l}\text { Helping animals survive or intentionally attracting } \\
\text { animals } \\
\text { "We plant this for the monkeys." }\end{array}$ \\
\hline Farming & $\begin{array}{l}\text { Farming for sustenance } \\
\text { "Our first dragon fruit harvest..." }\end{array}$ \\
\hline Education & $\begin{array}{l}\text { Education as a personal intervention for conservation } \\
\text { "We research and present on environmental problems } \\
\text { [in school]." }\end{array}$ \\
\hline $\begin{array}{l}\text { Control natural } \\
\text { disaster }\end{array}$ & $\begin{array}{l}\text { Helping to stop or clean up after a natural disaster } \\
\text { "I am dirty here from helping to put out the fire." }\end{array}$ \\
\hline Composting & $\begin{array}{l}\text { Turning food to soil conditioner } \\
\text { "We recycle fruit and vegetable rinds and use them as } \\
\text { a natural fertilizer." }\end{array}$ \\
\hline Cleanup & $\begin{array}{l}\text { Cleaning up trash or avoiding pollution } \\
\text { "We pick up trash to keep the environment clean." }\end{array}$ \\
\hline $\begin{array}{l}\text { Building } \\
\text { infrastructure }\end{array}$ & $\begin{array}{l}\text { Specific mentions of built infrastructure } \\
\text { "We built these roads..." }\end{array}$ \\
\hline $\begin{array}{l}\text { Alternative } \\
\text { transportation }\end{array}$ & $\begin{array}{l}\text { Eco-friendly transportation } \\
\text { "[We travel] by horse to protect the environment." }\end{array}$ \\
\hline
\end{tabular}

Dialogue regarding photographs in Santa Rosa reflected a close association with stewardship through agriculture, and a familiarity with transnational environmental movements, such as recycling. Two sisters mentioned that their school had always promoted respect and caring for nature. At one point, their teacher assigned them a project about the environment, so they decided to take used napkins and bottles from their house to create a turtle (Fig. 5a). They also collected the same materials from their aunt's house to help her recycle as well. Another community member took a different approach to conservation, particularly by growing plants in a garden in her backyard (Figure 5b). She explained how her plants help humans and the environment. When she tends to her plants, she becomes more relaxed and her stresses fade away. The coffee plants she grows help people by feeding them, and they provide her with profits when she decides to sell them at the local market. Moreover, the plants she grows clean the air by sequestering carbon dioxide. She also explained that she grows other plants for medicinal purposes, such as sage for stomach illness.

\section{Perceived environmental changes}

The prompt regarding perceived changes measured the participants' thoughts about how their natural environments have changed in the last 5 years (Table 6). The seven negative changes that both communities noted are infrastructure changes, erosion, dryness, deforestation, pollution, natural disasters, and changing biodiversity (Fig. 6). Although a few positive changes emerged from the photograph and workshop data, such as plant growth and economic gains, we show only the negative perceived changes because there were many more negative changes than positive changes overall.

Fig. 4. Code breakdown of responses to the question, "What do you do in your daily life to help conserve the environment?" Frequency refers to the number of times a code was raised by different members of the community.

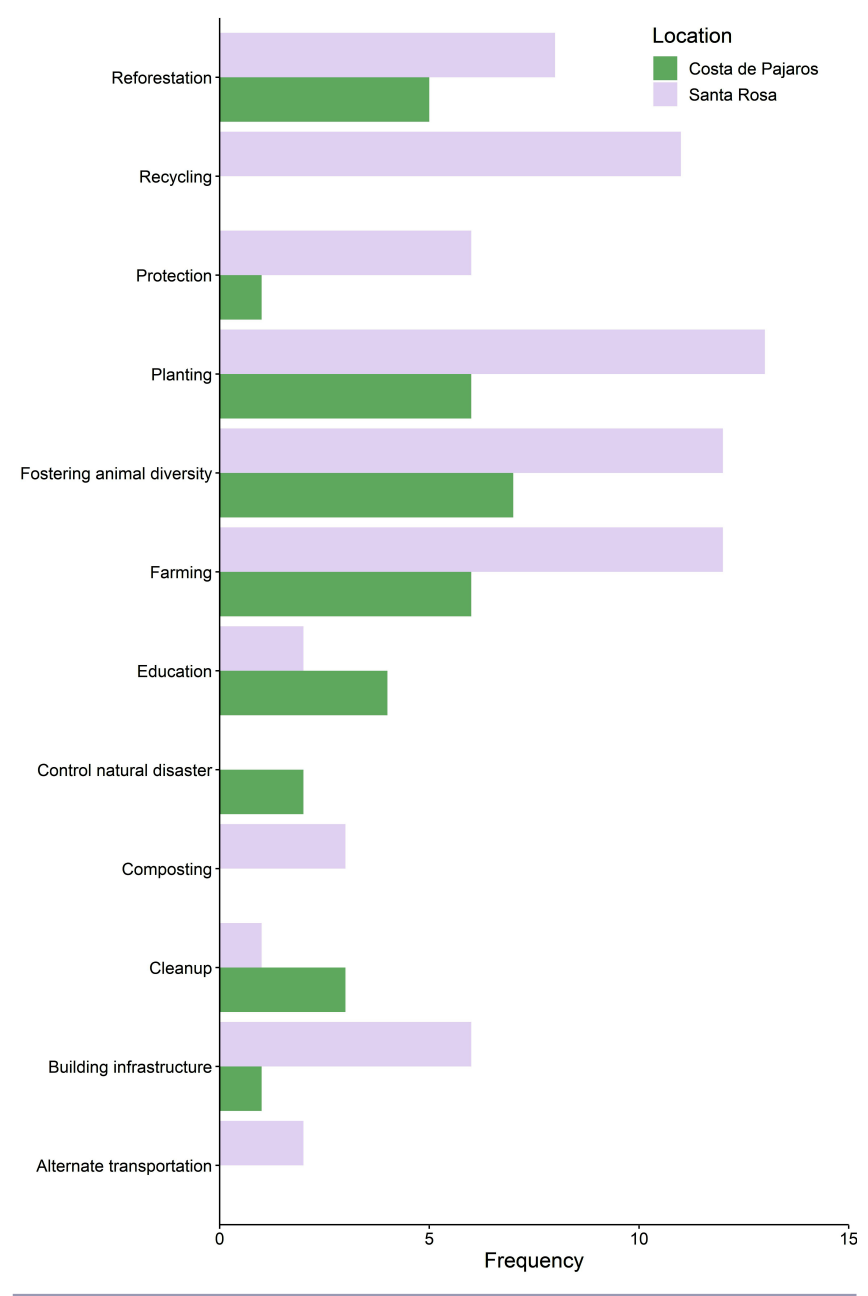

Fig. 5. Photographic responses from Santa Rosa in response to the prompt, "What do you do in your daily life to help conserve the environment?"

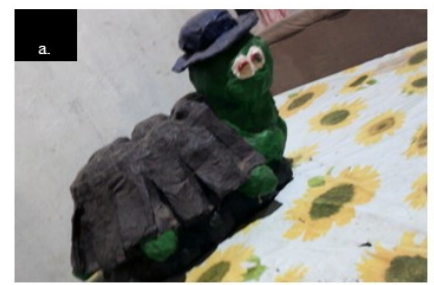

"A project with [recycled] napkins."

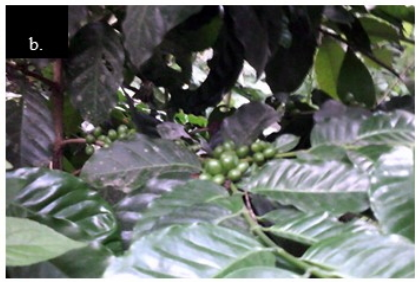

"[Coffee plants that I grow] help people and the environment." 
Table 6. Codes for perceived environmental changes (prompt 3).

\begin{tabular}{|c|c|}
\hline Code & Key words, concepts expressed \\
\hline Pollution & $\begin{array}{l}\text { General references to (new) pollution } \\
\text { "Look at the polluted beach." }\end{array}$ \\
\hline Natural disasters & $\begin{array}{l}\text { Includes landslides, hurricanes, storms, wildfires } \\
\text { "The landslide after the storm." }\end{array}$ \\
\hline Infrastructure & $\begin{array}{l}\text { Weathering, deterioration, or improvements to } \\
\text { infrastructure } \\
\text { "The school needs a lot of repairs." }\end{array}$ \\
\hline Erosion & $\begin{array}{l}\text { Soil erosion } \\
\text { "[When] the soil is bare, it begins to erode." }\end{array}$ \\
\hline Dryness & $\begin{array}{l}\text { Drought and a dry environment } \\
\text { "The trees dried up." }\end{array}$ \\
\hline Deforestation & $\begin{array}{l}\text { Humans cutting down trees } \\
\text { "There we have the trees cut down." }\end{array}$ \\
\hline $\begin{array}{l}\text { Changing } \\
\text { biodiversity }\end{array}$ & $\begin{array}{l}\text { Flora and fauna that have become more or less } \\
\text { abundant } \\
\text { "Some people poison the rivers, and the aquatic } \\
\text { species die." }\end{array}$ \\
\hline
\end{tabular}

Fig. 6. Code breakdown of responses to the question, "How has the environment changed in the last 5 years?" Frequency refers to the number of times a code was raised by different members of the community.

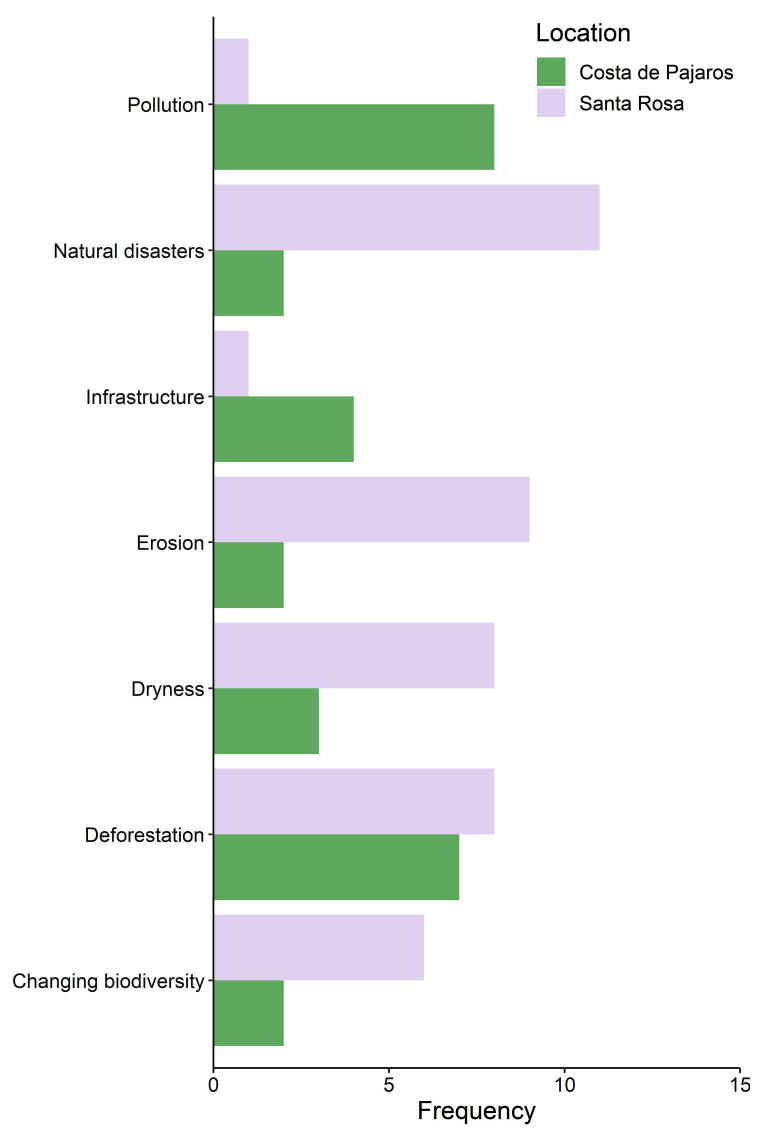

In descending order of frequency, the perceived changes for Costa de Pájaros were pollution, deforestation, infrastructure changes, dryness, erosion, biodiversity changes, and natural disasters (Fig. 6). One community member in Costa de Pájaros explained the changes in the river over time. She took the photo in Fig. 7a, and mentioned how the summers are hotter and drier, which is making the river shrink and flow less rapidly. In the winter, though, the rivers fill back up from the heavy rainfalls. The photo in Fig. $7 \mathrm{~b}$ shows trash on the beach, which represents the "pollution" code, the most frequent theme emerging from Costa de Pájaros. The participant who captured the photograph explained how "there is a lot of contamination on the beach; before it was blue and now it is brown; it is very dirty." Others from Costa de Pájaros mentioned that anglers throw bags of feces into the water and that the fuel burned for boats contaminates the water. The principal of the local elementary school also mentioned how most people treat the coastline like a garbage can, disrespecting and killing all the fish that live there. Participants also mentioned newly constructed cabins and roads, coded as "infrastructure." They mentioned that residents cut down trees for building, which in turn creates more environmental issues, such as dry land and erosion. Additionally, a few individuals noticed a decrease in fish size and an increase in boat size over the years. The fishing boats have become mechanized in recent years in Costa de Pájaros, which allows anglers to catch more fish and simultaneously cause overfishing.

Fig. 7. Photographic responses to the question, "How has the environment changed in the last 5 years?"
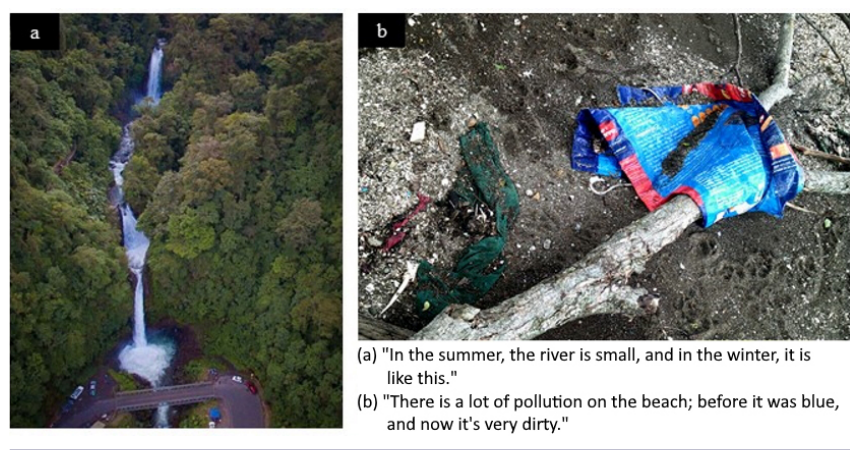

The perceived changes for Santa Rosa were natural disasters, erosion, dryness, deforestation, changing biodiversity, infrastructure changes, and pollution (Fig. 6). Many of the photographs from this group represented the "natural disaster" and "dryness" codes (Table 6). One person captured a photograph and titled it "landslide," explaining how there are many loose stones in the ground because of the landslides that occur in their mountainous town. She and others think that as the land becomes drier, the soil can more easily slide down the mountainside when it rains. Many others noted landslides when discussing perceived changes, but people also noted an increase in rainfall, intense storms, and hurricanes - all of which we included in the "natural disaster" code. One community member took a photo of a ravine that Hurricane Nate had destroyed a few months earlier. The hurricane pulled down many trees and brought sediment into the rivers. In turn, this slowed the flow of water and affected the species living in the water and the people who depend on the water downstream. 
Participants also noted plants, lands, and rivers that are becoming dry over time, all representing the "dryness" code. In addition, people mentioned erosion as a product of deforestation for the creation of farmland, which represented both the "erosion" and "deforestation" codes. Lastly, the participants noted how intensive farming practices, such as the use of pesticides, hurts the native flora and fauna.

\section{Model-based reasoning workshops}

The maps as boundary objects served to promote rich conversation about CES, environmental concerns, sense of stewardship, and conservation actions (Fig. 8). Maps, in general, are still relatively uncommon objects in rural Costa Rica, though this is quickly changing with the introduction of GPS navigation on cell phones. Participants spent time orienting themselves to the images of their communities and attempting to find known pieces of land, including some of their own farms. This stimulated dialogue about the practices undertaken by inhabitants of different areas. The nature of the method led to results that were difficult to distil into quantifiable themes, in contrast to the photovoice workshops. Instead, we summarized qualitative data from our observations of salient themes as recorded in field notes and audio recordings.

Fig. 8. Sample output from Stage 1 of the model-based reasoning workshop small groups in Costa de Pájaros (left) and Santa Rosa (right).

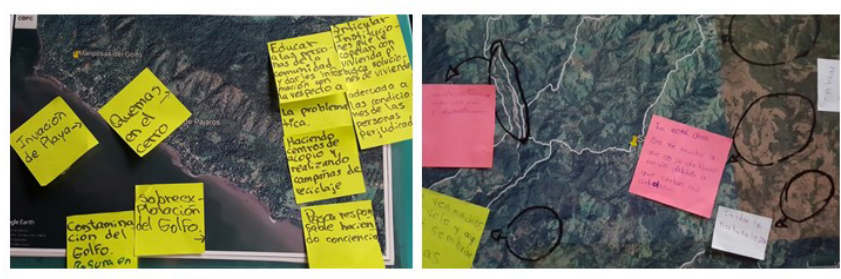

Key themes and observations in Santa Rosa

In Santa Rosa, a rural farming community, workshop participants typically moved the conversation in the direction of farm stewardship. Through sharing farming practices and bridging community members with nearby NGO representatives that work in conservation and reforestation, the MBR workshops served the function of introducing a number of community members to more sustainable farm practices. For example, one vocal participant who works in organic farming talked about the importance of practices he incorporates into his management strategy to conserve biodiversity and protect the watershed. This participant spoke extensively of the CES of knowledge systems and sense of place, communicating the importance of heritage and managing the landscape as something he would pass on to his children. At a different table, there was a heated discussion about the viability of sustainable farming practices, where a participant voiced, "We need to find a balance [between production and conservation]. We can't change the mentality of those who came before us, but we can change the current mindset and raise environmental awareness." Participants concurrently discussed organic agriculture and the benefits of planting native trees for windbreaks and sustenance.
Another salient conversation in Santa Rosa involved the importance of sense of place - of community organization and providing opportunities for the next generation to prevent emigration. Santa Rosa has begun to follow in the footsteps of other nearby Costa Rican farming villages that have been abandoned throughout the last generation. Many youth have left these rural areas in search of better opportunities in the city and in nearby tourism hot spots. Workshop participants voiced this concern: "We need to organize ourselves," one stated. Another chimed in, "[If we were better organized] perhaps that would have prevented so many people from leaving." Residents in Santa Rosa expressed particular interest in collaborating with neighboring communities in an effort to bring rural recreation and tourism to the area-an economic alternative to farming that might be able to revitalize the town. Conversations, subsequently, were shaped around this concern and the alternative future scenarios.

\section{Key themes and observations in Costa de Pájaros}

The conversations in Costa de Pájaros were distinct, reflecting the differences between the locations in terms of environments, livelihoods, and cultures. For example, fewer workshop participants in Costa de Pájaros were landowners, and the economic challenges facing the community were more salient, as was acute environmental deterioration (Fig. 9). The salient challenges discussed in the community were forest and farm fires, trash in the sea, insufficient housing, deforestation, burning trash, drought, overfishing, and illegal hunting. The solutions raised were associated largely with strengthening stewardship, community, and sense of place through raising awareness, reforestation, education, improving trash collection, improving community networking, and better enforcement of and respect for fishing regulations (Fig. 9).

Fig. 9. Shared environmental challenges ("retos") and potential action steps ("soluciones") in the Costa de Pájaros model-based reasoning workshop.

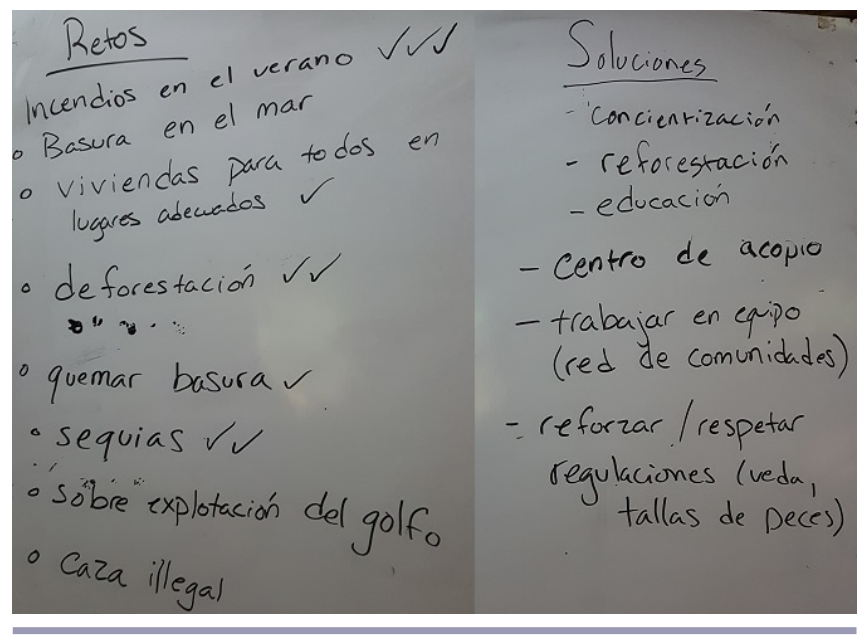

The general dialogue in Costa de Pájaros centered on the key economic resource in the region, the sea. One primary concern was the continual encroachment upon the beach: building nearly up to the shoreline (despite legal restrictions), fishing without permits, and fishing within no-take zones and during fishery closures. These activities have resulted in the pollution of the 
beach: fuel contamination, discarded nets, seepage of local sewage, and illegal dumping. Workshop participants expressed awareness that these behaviors occur because of economic necessity, but that they also prevent the community from thriving economically.

The maps provided a safe negotiating space for discussing difficult and taboo subjects, as participants circled areas of concern and made notes about what they saw (and did not see) in the images (Fig. 8). One group discussed the topic of beach encroachment in a small group and decided that nothing could be done about it. A different group boldly stepped up at the final presentation to discuss environmental concerns with everyone: "...there is a problem that no one wants to discuss...the invasion of the beach by those living nearby, and the pollution." This individual shared a monologue of sorts: that it is a difficult issue but avoiding it will not make it go away, that everyone values the sea, and everyone needs the sea, that they might not fix the problem, but that perhaps they can do a better job as stewards of the ocean "together, working as a community." At the end of his speech, applause erupted, which demonstrated a release of the tension this topic had created, and perhaps relief that the forum had provided a space to discuss these issues.

\section{Exit survey results}

The exit survey conducted at the end of each MBR workshop indicated that only $47 \%$ of people who attended the workshops had prior contact with conservation organizations. When asked, "After today's workshop, how optimistic do you feel about future collaborations on sustainability initiatives in the zone?", the average answer was 9.76 out of 10. Likewise, when asked, "After today's workshop, how energized do you feel about the idea of applying sustainable methods in your community?", the average answer was again 9.76 out of 10 . All participants answered that they would like to participate in a similar workshop at a different time. When asked why, most answers echoed the sentiment expressed by one of the key participants: "Every meeting is like a capacitación [formal training]." Some said that it is important to learn about biodiversity, and that this awareness can make a difference in how people interact with their surroundings. Others said they found the meetings energizing and motivatingindicating that the workshops had instilled a sense of pride about their communities.

\section{DISCUSSION AND CONCLUSIONS}

\section{Contextualizing cultural ecosystem services through dialogue workshops}

The process of dialogue unveils a rich complexity of values that has the potential to contribute to a more robust understanding of CES. In the photovoice workshops, dialogue about photographs deepened stakeholder engagement and allowed the participants to express a multiplicity of values regarding an object, prompt, or experience. For example, the coffee plant in Fig. 5b could be taken at face value, understanding that it represents planting as caring for the environment. However, the conversation about the photograph generated a shared knowledge of the relational values held for this particular action - coffee is representative of the history of Santa Rosa, and is deeply entwined with a sense of place. It is also a plant known to provide oxygen to the environment and sequester carbon at the same time that it increases the beauty of the region. These multiple values were shown in the photograph but were revealed and shared through dialogue.

Likewise, in the MBR workshops, CES emerged as participants discussed livelihoods and lifestyles interlinked with the surrounding ecosystem services. The boundary negotiating objects (i.e., the maps) inspired dialogue about the state of the participants' communities and the physical aspects of the land that create meaning in their lives, which revealed the environment as a space of discord and negotiation, as well as shared meaning. The dialogue in Santa Rosa centered on sustainable farming and the importance of trees, which reflected the fluidity of knowledge systems and the ways in which values are reinforced through interaction with the environment, nearby communities, and each other. In Costa de Pájaros, dialogue centered on the sea as a contested space, with various possibilities and meanings depending on the positioning of the local community members.

The dialogue in Costa de Pájaros was particularly representative of CES values and conservation conflict. Costa Rican law makes all beaches public (Ley No. 6043). Permits are required for fishing in the adjacent fishery, but it is commonly known that many people fish without permits. Simultaneously, the lack of tourism in this beach area lies in stark contrast to much of Costa Rica, where beaches have been developed by powerful investors for the enjoyment of a primarily foreign populace, despite some of the restrictions placed by the maritime law (van Noorloos 2011). Hence, the sea is a common-pool resource that different actors approach with unique agendas. It is a potential battleground, as demonstrated by research on local and foreign sport surfer conflicts on the Pacific Coast (Usher and Gómez 2016). The conversation about encroachment on the coastline in Costa de Pájaros highlighted the ways in which participants felt robbed of provisioning services, at the same time that it mirrored the national conversation about who owns access to ecosystem services (and what should be the vision for their future use) (Campbell 2002, Honey et al. 2010). In contrast to these other studies, competing visions for the Costa de Pájaros coastline were held by Costa Ricans, as opposed to reflecting local resident conflicts with foreign investors. These stakeholders expressed frustration about the collapse of both the aesthetic and provisioning services that the sea could provide; the fishery is in danger of collapse, and pollution prevents tourism development.

In addition to value elicitation, our workshops collectively served to bring to a public forum private concerns and conversations, and elucidated value systems and subsequently energized participants to move toward concrete action steps. The mere range of participants in the MBR workshops, including local residents and regional conservationists who worked for NGOs outside of each community, reflected the enthusiasm surrounding the process. The MBR workshops provided a forum for learning and exchange, in addition to dialogue and reflection. When asked, community members described feeling invigorated by the process and hoped to participate in future discussions, citing the importance of learning and conversing on issues that are central to their communities. We were later told by the local NGO representative who attended the Santa Rosa MBR workshop that there had been substantial follow-up, as many community members subsequently contacted the NGO to participate in 
reforestation programs. The photovoice workshops were likewise a "fun" learning and exchange experience for participants. A frequent comment among photovoice workshop participants related to the particular ability of the camera lens to reframe how they experience the quotidian. One participant stated specifically, "How interesting, right? I see these things everyday but don't recognize how beautiful they are." The process of taking photographs provided a novel way for participants to engage with the environment, and the workshops themselves offered a space for reflection and exchange. Overall, the results indicate that in addition to value elicitation, the workshops were successful in fostering social capital and motivating future participation in stewardship and conservation activities.

As a methodology, dialogue workshops represent an important advancement in deliberation and value elicitation, revealing aspects of CES values that are obscured through popular economic valuation measures. While economic valuation may solicit diverse ecosystem services values (de Groot et al. 2002), and even include non-use values in the overall value framework and estimation (Brown et al. 2007), the final stage of the valuation process will often reduce these values to a monetary exchange value (Champ et al. 2003). Although monetary valuation facilitates alterative scenario comparison for decision-makers, it assumes values are commensurable and that stakeholders are fully able to comprehend and rank the value of different components that contribute to individual and communal well-being (Martinez-Alier et al. 1998). This practice endures, even though considerable research demonstrates that valuation tools mistakenly treat context-dependent decisions as rational, salient, and universal (Sen 1977, Solow 1985, Ostrom 1998, Gowdy and Erickson 2005). Dialogue, then, emerges in stark contrast to valuation - a process that focuses less on extractable information and instead brings stakeholders together, engages them in the consideration of scenarios, and ultimately results in more informed, democratic decision-making.

We assert that dialogue is a key component of a broader toolkit necessary to engage stakeholders in the diversity of CES in any given context. Multiple methods are necessary to triangulate values and potentially lead to a more holistic understanding of complex value systems and greater inclusion among stakeholders (Norton and Noonan 2007, Spangenberg and Settele 2010, Satz et al. 2013, Jacobs et al. 2016). This might include the monetary valuation of some components of CES, coupled with ethnography, to understand the meaning behind valuation measures and diverse perspectives on ecosystem services (Allen and Colson 2019). Some novel techniques include crowdsourcing internet photographs to identify CES (Gliozzo et al. 2016) and employing mixed methods, coupling surveys with semi-structured interviews to understand CES (Gould et al. 2014). Of particular interest, in mixed methodologies, economic deliberative valuation employs stated preference scenarios as the prompts for deliberation about the value of ecosystem services (Howarth and Wilson 2006, Spash 2007, 2008). More inclusive valuation techniques (Satterfield 2001), including the dialogue methods we have described, can serve to elaborate on the meaning and context of CES and the translation of these values into community organizing, policy, and action.

\section{Trade-offs across methods between value elicitation and} stakeholder engagement

Our methods also revealed a fundamental challenge in conceptualizing ecosystem services and engaging stakeholders in conservation - a challenge central to the nature of scientific research, value elicitation, and knowledge extraction. We found a tension in our research design between the emphasis on structure, replicability, and value elicitation (extractable knowledge) that was highlighted more in the photovoice methods, and the organic process of the MBR workshops, which warrants further consideration.

We did not quantify the values that arose in the MBR workshops because the purpose was not to extract information but rather to engage in process. This emphasis on process, however, made it more difficult to categorize CES arising from the MBR workshops. The decision to place the recorders in an inconspicuous location, and the organic nature of the boundary negotiating objects in relation to the developing dialogue led to inconsistent "sampling" and "results"-more scientific concepts would have been emphasized if the purpose of the MBR workshops had been to extract information. Salient concerns and underlying ecosystem service priorities still emerged (Fig. 9), and the MBR workshops appeared more successful in strengthening participant sense of place and communal stewardship. It is our impression that the open, non-extractive nature of the MBR workshops inspired trust in the process among participants. The lead author's years of experience in the region, combined with a workshop design that did not appear to have ulterior motives, resulted in MBR workshops that placed an emphasis on brainstorming and sharing. The role of the researcher, in this case, became more akin to a consultant or boundary worker by supporting local concerns and using "expertise" to foster connections across organizations and with outside actors from NGOs. We were not able to continue repeated MBR workshops in the region, which would have been ideal for strengthening connections and supporting action steps. However, continued contact with stakeholders suggests that the connections forged during the workshops endured in the following months.

The photovoice workshops used a methodology that allowed for a direct categorization and quantification of participant values. For example, we were able to compare the values that create a sense of belonging across the two communities, and to rank the importance of CES such as aesthetic values and recreational values. Photovoice has the distinct advantage of removing the potential barrier of verbal expression, but it can suffer from drawbacks similar to those of interviews and surveys. We obtained only a limited snapshot of participant perspectives because the complexity of values were forced through the lens of the camera. Other research on CES value elicitation has demonstrated similar challenges. Participatory mapping is a valuable tool for including stakeholders in the identification of places of high CES value (McCall and Minang 2005, Plieninger et al. 2013, Darvill and Lindo 2015), but it also relies on a particular framing of the landscape that can result in unintentional exclusions (Elwood 2006). Perhaps more problematic, the technology itself is not accessible to all stakeholders alike. For example, the lead author had experience working with participatory mapping on another occasion in rural Costa Rica and found that the lack of familiarity with maps themselves would have forced stakeholders to express 
values through an artificial medium, which would lose meaning in translation. When comparing the results of the photovoice sessions to those of the MBR workshops, the process of exploring dialogue and values in the MBR workshops was revealed to be more organic and authentic, precisely because it did not place particular requirements or restrictions on the format of participation. This mirrors the method of ethnography, which anthropologists frequently claim provides the most holistic understanding of culture in context.

Hence, the fundamental question remains-How does research move forward when the "best" process for stakeholder engagement is the most organic but perhaps also the one that least lends itself to replicable methodology and the creation of "scientific" knowledge? Dialogue workshops revealed the thin line between research, community engagement, and environmental action. The MBR workshops had a clear community-organizing imperative: they grew out of previous research in the region, they were inspired and organized according to individual community needs and interests, and they provided a forum for connecting stakeholders who had minimal prior contact. However, the workshops did not generate reproducible knowledge. Photovoice provided a means of capturing concepts and values, and stimulating dialogue about those concerns. Quotes from participants revealed that the camera lens literally and figuratively gave them a different perspective on the world they encountered in their daily lives. Seeing the quotidian through a camera unveiled the beauty of the local environs and the importance of the things they might overlook in daily interactions. This result parallels studies on the ways in which monetary valuation itself changes participants' values, forcing them to distil complex value systems into simplistic monetary exchange values, and in the process, potentially training them to view the environment through the lens of cost-benefit analysis and market mentality (Matulis 2014, Allen 2018). If all research trains stakeholders in the lens of the methodology itself, perhaps researchers who are attempting to understand ecosystem services values need to fully accept the importance of process and give it equal weight to the importance of knowledge generation, while exercising caution in the types of methods undertaken because we are always doing more than merely extracting information.

Responses to this article can be read online at: https://www.ecologyandsociety.org/issues/responses. php/12187

\section{Acknowledgments:}

This research was partially supported by the Wenner Gren Foundation Engaged Anthropology Grant; Gr. EAG-122. We are grateful for the participation and support of community members in Santa Rosa and Costa de Pajaros in this research, as well as the collaboration of administration and supporting members of local conservation organizations, including the Bellbird Biological Corridor. We are further thankful for the comments provided by two anonymous reviewers, which greatly improved the quality of this manuscript.

\section{Data Availability:}

The data that support the findings of this study are available on request from the corresponding author. The data are not publicly available because they contain information that could compromise the privacy of research participants.

\section{LITERATURE CITED}

Adams, W. 2004. Against extinction: the story of conservation. Earthscan Publications, London, UK. https://doi. org/10.4324/9781849770415

Allen, K. 2018. Why exchange values are not environmental values: explaining the problem with neoliberal conservation. Conservation \& Society 16(3):243-256. https://doi.org/10.4103/cs. cs $17 \quad 68$

Allen, K. E., and G. Colson. 2019. Understanding PES from the ground up: a combined choice experiment and interview approach to understanding PES in Costa Rica. Sustainability Science 14 (2):391-404. https://doi.org/10.1007/s11625-018-00653-w

Bennett, N. J., and P. Dearden. 2013. A picture of change: using photovoice to explore social and environmental change in coastal communities on the Andaman Coast of Thailand. Local Environment 18(9):983-1001. https://doi.org/10.1080/13549839.2012.748733

Berbés-Blázquez, M. 2012. A participatory assessment of ecosystem services and human wellbeing in rural Costa Rica using photo-voice. Environmental Management 49(4):862-875. https:// doi.org/10.1007/s00267-012-9822-9

Bohm, D., and L. Nichol. 1996. On dialogue. Routledge, London, UK.

Boyd, J., and S. Banzhaf. 2007. What are ecosystem services? The need for standardized environmental accounting units. Ecological Economics 63(2):616-626. https://doi.org/10.1016/j.ecolecon.2007.01.002

Brown, G., and N. Fagerholm. 2015. Empirical PPGIS/PGIS mapping of ecosystem services: a review and evaluation. Ecosystem Services 13:119-133. https://doi.org/10.1016/j.ecoser.2014.10.007

Brown, T. C., J. C. Bergstrom, and J. B. Loomis. 2007. Defining, valuing, and providing ecosystem goods and services. Natural Resources Journal 47:329-376.

Bunse, L., O. Rendon, and S. Luque. 2015. What can deliberative approaches bring to the monetary valuation of ecosystem services? A literature review. Ecosystem Services 14:88-97. https:// doi.org/10.1016/j.ecoser.2015.05.004

Campbell, L. M. 2002. Conservation narratives in Costa Rica: conflict and co-existence. Development and Change 33(1):29-56. https://doi.org/10.1111/1467-7660.00239

Carlson, E. D., J. Engebretson, and R. M. Chamberlain. 2006. Photovoice as a social process of critical consciousness. Qualitative Health Research 16(6):836-852. https://doi. org/10.1177/1049732306287525

Castleden, H., T. Garvin , and Huu-ay-aht First Nation. 2008. Modifying Photovoice for community-based participatory Indigenous research. Social Science \& Medicine 66(6):1393-1405. https://doi.org/10.1016/j.socscimed.2007.11.030 
Cavender-Bares, J., P. Balvanera, E. King, and S. Polasky. 2015. Ecosystem service trade-offs across global contexts and scales. Ecology and Society 20(1):22. https://doi.org/10.5751/ES-07137-200122

Champ, P. A., K. J. Boyle, and T. C. Brown, editors. 2003. A primer on nonmarket valuation. Kluwer Academic Publishers, Dordrecht, Netherlands. https://doi.org/10.1007/978-94-007-0826-6

Chan, K. M. A., P. Balvanera, K. Benessaiah, M. Chapman, S. Díaz, E. Gómez-Baggethun, R. Gould, N. Hannahs, K. Jax, S. Klain, et al. 2016. Opinion: Why protect nature? Rethinking values and the environment. Proceedings of the National Academy of Sciences of the United States of America 113(6):1462-1465. https://doi.org/10.1073/pnas.1525002113

Chan, K. M. A., J. Goldstein, T. Satterfield, N. Hannahs, K. Kikiloi, R. Naidoo, N. Vadeboncoeur, and U. Woodside. 2011. Cultural services and non-use values. In H. Tallis, T. H. Ricketts, G. C. Daily, and S. Polasky, editors. Natural capital: theory and practice of mapping ecosystem services. Oxford University Press, New York, USA. https://doi.org/10.1093/acprof: oso/9780199588992.003.0012

Chan, K. M. A., A. D. Guerry, P. Balvanera, S. Klain, T. Satterfield, X. Basurto, A. N. N. Bostrom, R. Chuenpagdee, R. Gould, B. S. Halpern, et al. 2012a. Where are cultural and social in ecosystem services? A framework for constructive engagement. BioScience 62(8):744-756. https://doi.org/10.1525/bio.2012.62.8.7

Chan, K. M. A., T. Satterfield, and J. Goldstein. $2012 b$. Rethinking ecosystem services to better address and navigate cultural values. Ecological Economics 74:8-18. https://doi. org/10.1016/j.ecolecon.2011.11.011

Costanza, R., R. D’arge, R. de Groot, S. Farber, M. Grasso, B. Hannon, K. Limburg, S. Naeem, R. V. O’Neill, J. Paruelo, R. G. Raskin, P. Sutton, and M. van den Belt. 1997. The value of the world's ecosystem services and natural capital. Nature 387 (6630):253-260. https://doi.org/10.1038/387253a0

Cronon, W. 1995. The trouble with wilderness; or, getting back to the wrong nature. In W. Cronon, editor. Uncommon ground: toward reinventing nature. W.W. Norton \& Co., New York,USA. https://doi.org/10.2307/3985059

Daily, G. C., S. Alexander, P. R. Ehrlich, L. H. Goulder, J. Lubchenco, P. A. Matson, and H. A. Mooney. 1997. Nature's services: societal dependence on natural ecosystems. Island Press, Washington, D.C., USA.

Daily, G. C., S. Polasky, J. Goldstein, P. M. Kareiva, H. A. Mooney, L. Pejchar, T. H. Ricketts, J. Salzman, and R. Shallenberger. 2009. Ecosystem services in decision making: time to deliver. Frontiers in Ecology and the Environment 7(1):21-28. https://doi.org/10.1890/080025

Dalton, G. 1961. Economic theory and primitive society. American Anthropologist 63(1):1-25. https://doi.org/10.1525/ $\underline{\text { aa.1961.63.1.02a00010 }}$

Daniel, T. C., A. Muhar, A. Arnberger, O. Aznar, J. W. Boyd, K. M. Chan, R. Costanza, T. Elmqvist, C. G. Flint, and P. H. Gobster. 2012. Contributions of cultural services to the ecosystem services agenda. Proceedings of the National Academy of Sciences of the
United States of America 109(23):8812-8819. https://doi. org/10.1073/pnas.1114773109

Darvill, R., and Z. Lindo. 2015. Quantifying and mapping ecosystem service use across stakeholder groups: implications for conservation with priorities for cultural values. Ecosystem Services 13:153-161. https://doi.org/10.1016/j.ecoser.2014.10.004

de Groot, R. S., R. Alkemade, L. Braat, L. Hein, and L. Willemen. 2010. Challenges in integrating the concept of ecosystem services and values in landscape planning, management and decision making. Ecological Complexity 7(3):260-272. https://doi. org/10.1016/j.ecocom.2009.10.006

de Groot, R. S., M. A. Wilson, and R. M. J. Boumans. 2002. A typology for the classification, description and valuation of ecosystem functions, goods and services. Ecological Economics 41(3):393-408. https://doi.org/10.1016/S0921-8009(02)00089-7

Dessel, A., and M. E. Rogge. 2008. Evaluation of intergroup dialogue: a review of the empirical literature. Conflict Resolution Quarterly 26(2):199-238. https://doi.org/10.1002/crq.230

Díaz, S., S. Demissew, J. Carabias, C. Joly, M. Lonsdale, N. Ash, A. Larigauderie, J. R. Adhikari, S. Arico, A. Báldi, et al. 2015. The IPBES Conceptual Framework - connecting nature and people. Current Opinion in Environmental Sustainability 14:1-16. https://doi.org/10.1016/j.cosust.2014.11.002

Elwood, S. 2006. Negotiating knowledge production: the everyday inclusions, exclusions, and contradictions of participatory GIS research. Professional Geographer 58 (2):197-208. https://doi.org/10.1111/j.1467-9272.2006.00526.x

Falkenmark, M., L. Gottschalk, J. Lundqvist, and P. Wouters. 2004. Towards integrated catchment management: increasing the dialogue between scientists, policy-makers and stakeholders. International Journal of Water Resources Development 20 (3):297-309. https://doi.org/10.1080/0790062042000248619

Fisher, B., R. K. Turner, and P. Morling. 2009. Defining and classifying ecosystem services for decision making. Ecological Economics 68(3):643-653. https://doi.org/10.1016/j.ecolecon.2008.09.014

Gliozzo, G., N. Pettorelli, and M. Haklay. 2016. Using crowdsourced imagery to detect cultural ecosystem services: a case study in South Wales, UK. Ecology and Society 21(3):6. https://doi.org/10.5751/ES-08436-210306

Gould, R. K., N. M. Ardoin, U. Woodside, T. Satterfield, N. Hannahs, and G. C. Daily. 2014. The forest has a story: cultural ecosystem services in Kona, Hawai'i. Ecology and Society 19 (3):55. https://doi.org/10.5751/ES-06893-190355

Gowdy, J., and J. D. Erickson. 2005. The approach of ecological economics. Cambridge Journal of Economics 29(2):207-222. https://doi.org/10.1093/cje/bei033

Graeber, D. 2001. Toward an anthropological theory of value: the false coin of our own dreams. Palgrave, New York,USA. https:// doi.org/10.1057/9780312299064

Gregory, R., L. Failing, M. Harstone, G. Long, T. McDaniels, and D. Ohlson. 2012. Structured decision making: a practical guide to environmental management choices. John Wiley \& Sons. https:// doi.org/10.1002/9781444398557 
Gurin, P., B. R. A. Nagda, and X. Zuniga. 2013. Dialogue across difference: practice, theory, and research on intergroup dialogue. Russell Sage Foundation, New York, USA.

Hanley, N., S. Mourato, and R. E. Wright. 2001. Choice modelling approaches: a superior alternative for environmental valuation? Journal of Economic Surveys 15(3):435-462. https://doi. org/10.1111/1467-6419.00145

Harper, D. 2002. Talking about pictures: a case for photo elicitation. Visual Studies 17(1):13-26. https://doi. org/10.1080/14725860220137345

Healey, G. K., K. Magner, R. Ritter, R. Kamookak, A. Aningmiuq, B. Issaluk, K. Mackenzie, L. Allardyce, A. Stockdale, and P. Moffit. 2011. Community perspectives on the impact of climate change on health in Nunavut, Canada. Arctic 64(1):89-97. https://doi.org/10.14430/arctic4082

Honey, M., E. Vargas, and W. H. Durham. 2010. Impact of tourism related development on the Pacific Coast of Costa Rica: summary report. Stanford University and Center for Responsible Travel, Washington, D.C., USA.

Howarth, R. B., and M. A. Wilson. 2006. A theoretical approach to deliberative valuation: aggregation by mutual consent. Land Economics 82(1):1-16. https://doi.org/10.3368/le.82.1.1

Jacobs, S., N. Dendoncker, B. Martín-López, D. N. Barton, E. Gómez-Baggethun, F. Boeraeve, F. L. McGrath, K. Vierikko, D. Geneletti, K. J. Sevecke, et al. 2016. A new valuation school: integrating diverse values of nature in resource and land use decisions. Ecosystem Services 22:213-220. https://doi.org/10.1016/ j.ecoser.2016.11.007

Jax, K., D. N. Barton, K. M. A. Chan, R. de Groot, U. Doyle, U. Eser, C. Görg, E. Gómez-Baggethun, Y. Griewald, W. Haber, et al. 2013. Ecosystem services and ethics. Ecological Economics 93:260-268. https://doi.org/10.1016/j.ecolecon.2013.06.008

Kenter, J. O. 2016. Integrating deliberative monetary valuation, systems modelling and participatory mapping to assess shared values of ecosystem services. Ecosystem Services 21:291-307. https://doi.org/10.1016/j.ecoser.2016.06.010

Kenter, J. O., T. Hyde, M. Christie, and I. Fazey. 2011. The importance of deliberation in valuing ecosystem services in developing countries-evidence from the Solomon Islands. Global Environmental Change 21(2):505-521. https://doi. org/10.1016/j.gloenvcha.2011.01.001

Klain, S. C., and K. M. Chan. 2012. Navigating coastal values: participatory mapping of ecosystem services for spatial planning. Ecological Economics 82:104-113. https://doi.org/10.1016/j. ecolecon.2012.07.008

Klain, S. C., P. Olmsted, K. M. Chan, and T. Satterfield. 2017. Relational values resonate broadly and differently than intrinsic or instrumental values, or the New Ecological Paradigm. PLoS One 12(8):e0183962. https://doi.org/10.1371/journal.pone.0183962

Koppes, C. R. 1988. Efficiency, equity, esthetics: shifting themes in American conservation. Pages 230-251 in D. Worster, editor. The ends of the Earth: perspectives on modern environmental history. Cambridge University Press, Cambridge, UK. https://doi. org/10.1017/CBO9781139173599.011
Kosoy, N., and E. Corbera. 2010. Payments for ecosystem services as commodity fetishism. Ecological Economics 69(6):1228-1236. https://doi.org/10.1016/j.ecolecon.2009.11.002

Lee, C. P. 2007. Boundary negotiating artifacts: unbinding the routine of boundary objects and embracing chaos in collaborative work. Computer Supported Cooperative Work (CSCW) 16 (3):307-339. https://doi.org/10.1007/s10606-007-9044-5

Lienhoop, N., and M. Völker. 2016. Preference refinement in deliberative choice experiments for ecosystem service valuation. Land Economics 92(3):555-577. https://doi.org/10.3368/le.92.3.555

Maclean, K., and L. Cullen. 2009. Research methodologies for the co-production of knowledge for environmental management in Australia. Journal of the Royal Society of New Zealand 39:205-208. https://doi.org/10.1080/03014220909510581

Marková, I., P. Linell, M. Grossen, and A. Salazar Orvig. 2007. Dialogue in focus groups: exploring socially shared knowledge. Equinox Publishing.

Martinez-Alier, J., G. Munda, and J. O’Neill. 1998. Weak comparability of values as a foundation for ecological economics. Ecological Economics 26(3):277-286. https://doi.org/10.1016/ S0921-8009(97)00120-1

Mattouk, M., and S. N. Talhouk. 2017. A content analysis of nature photographs taken by Lebanese rural youth. PloS One 12 (5):e0177079. https://doi.org/10.1371/journal.pone.0177079

Matulis, B. S. 2014. The economic valuation of nature: a question of justice? Ecological Economics 104:155-157. https://doi. org/10.1016/j.ecolecon.2014.04.010

Mavrommati, G., M. E. Borsuk, and R. B. Howarth. 2017. A novel deliberative multicriteria evaluation approach to ecosystem service valuation. Ecology and Society 22(2):39. https://doi. org/10.5751/ES-09105-220239

McAfee, K., and E. N. Shapiro. 2010. Payments for ecosystem services in Mexico: nature, neoliberalism, social movements, and the state. Annals of the Association of American Geographers 100 (3):579-599. https://doi.org/10.1080/00045601003794833

McCall, M. K., and P. A. Minang. 2005. Assessing participatory GIS for community-based natural resource management: claiming community forests in Cameroon. Geographical Journal 171(4):340-356. https://doi.org/10.1111/j.1475-4959.2005.00173. $\underline{x}$

Millenium Ecosystem Assessment. 2003. Ecosystems and human well-being: a framework for assessment. Island Press, Washington, D.C., USA.

Munn, N. 1986. The fame of gawa: a symbolic study of value transformation in Massim (Papua New Guinea) society. Cambridge University Press, Cambridge, UK.

Nelson, E., G. Mendoza, J. Regetz, S. Polasky, H. Tallis, D. R. Cameron, K. M. A. Chan, G. C. Daily, J. Goldstein, P. M. Kareiva, et al. 2009. Modeling multiple ecosystem services, biodiversity conservation, commodity production, and tradeoffs at landscape scales. Frontiers in Ecology and the Environment 7(1):4-11. https:// doi.org/10.1890/080023 
Nersessian, N. J. 1999. Model-based reasoning in conceptual change. Pages 5-222 in L. Magnani, N. J. Nersessian, and P. Thagard, editors. Model-based reasoning in scientific discovery. Springer. https://doi.org/10.1007/978-1-4615-4813-3_1

Norton, B. G., and D. Noonan. 2007. Ecology and valuation: big changes needed. Ecological Economics 63(4):664-675. https://doi. org/10.1016/j.ecolecon.2007.02.013

Ostrom, E. 1998. A behavioral approach to the rational choice theory of collective action: presidential address, American Political Science Association. American Political Science Review 92(1):1-22. https://doi.org/10.2307/2585925

Palomo, I., B. Martín-López, P. Zorrilla-Miras, D. García Del Amo, and C. Montes. 2014. Deliberative mapping of ecosystem services within and around Doñana National Park (SW Spain) in relation to land use change. Regional Environmental Change 14 (1):237-251. https://doi.org/10.1007/s10113-013-0488-5

Partelow, S., M. Fujitani, V. Soundararajan, and A. Schlüter. 2019. Transforming the social-ecological systems framework into a knowledge exchange and deliberation tool for comanagement. Ecology and Society 24(1):15. https://doi.org/10.5751/ES-10724-240115

Pascual, U., P. Balvanera, S. Díaz, G. Pataki, E. Roth, M. Stenseke, R. T. Watson, E. Başak Dessane, M. Islar, E. Kelemen, et al. 2017. Valuing nature's contributions to people: the IPBES approach. Current Opinion in Environmental Sustainability 26-27:7-16. https://doi.org/10.1016/j.cosust.2016.12.006

Pascual, U., J. Phelps, E. Garmendia, K. Brown, E. Corbera, A. Martin, E. Gomez-Baggethun, and R. Muradian. 2014. Social equity matters in payments for ecosystem services. BioScience 64 (11):1027-1036. https://doi.org/10.1093/biosci/biu146

Paudyal, K., H. Baral, B. Burkhard, S. P. Bhandari, and R. J. Keenan. 2015. Participatory assessment and mapping of ecosystem services in a data-poor region: case study of community-managed forests in central Nepal. Ecosystem Services 13:81-92. https://doi.org/10.1016/j.ecoser.2015.01.007

Pennington, D., G. Bammer, A. Danielson, D. Gosselin, J. Gouvea, G. Habron, D. Hawthorne, R. Parnell, K. Thompson, S. Vincent, and C. Wei. 2016. The EMBeRS project: employing model-based reasoning in socio-environmental synthesis. Journal of Environmental Studies and Sciences 6(2):278-286. https://doi. org/10.1007/s13412-015-0335-8

Plieninger, T., S. Dijks, E. Oteros-Rozas, and C. Bieling. 2013. Assessing, mapping, and quantifying cultural ecosystem services at community level. Land Use Policy 33:118-129. https://doi. org/10.1016/j.landusepol.2012.12.013

Polanyi, K. 1957. The great transformation. Beacon Press, Boston, Massachusetts, USA. https://doi.org/10.1002/9780470755679. $\underline{\operatorname{ch} 4}$

Polasky, S., E. Nelson, J. Camm, B. Csuti, P. Fackler, E. Lonsdorf, C. Montgomery, D. White, J. Arthur, B. Garber-Yonts, et al. 2008. Where to put things? Spatial land management to sustain biodiversity and economic returns. Biological Conservation 141 (6):1505-1524. https://doi.org/10.1016/j.biocon.2008.03.022
Proctor, W., and M. Dreschler. 2006. Deliberative multicriteria evaluation. Environment and Planning C: Politics and Space 24:169-190. https://doi.org/10.1068/c22s

Ryan, G. W., and H. R. Bernard. 2000. Data management and analysis methods. In N. Denzin and Y. Lincoln, editors. Handbook of Qualitative Research. Second edition. Sage Publications, Thousand Oaks, California, USA.

Ryan, G. W., and H. R. Bernard. 2003. Techniques to identify themes. Field Methods 15(1):85-109. https://doi.org/10.1177/152$\underline{5822 X 02239569}$

Satterfield, T. 2001. In search of value literacy: suggestions for the elicitation of environmental values. Environmental Values 10 (3):331-359. https://doi.org/10.3197/096327101129340868

Satz, D., R. K. Gould, K. M. A. Chan, A. Guerry, B. Norton, T. Satterfield, B. S. Halpern, J. Levine, U. Woodside, N. Hannahs, et al. 2013. The challenges of incorporating cultural ecosystem services into environmental assessment. Ambio 42(6):675-684. https://doi.org/10.1007/s13280-013-0386-6

Schatz, M., R. Furman, and L. E. Jenkins. 2003. Space to grow: using dialogue techniques for multinational, multicultural learning. International Social Work 46(4):481-494. https://doi. org/10.1177/0020872803464005

Sen, A. K. 1977. Rational fools: a critique of the behavioral foundations of economic theory. Philosophy \& Public Affairs 6 (4):317-344.

Sistema Nacional de Areas de Conservacion (SINAC). 2009. Plan Estratégico del Programa Nacional de Corredores Biológicos de Costa Rica para el quinquenio 2009-2014. San José, Costa Rica.

Small, N., M. Munday, and I. Durance. 2017. The challenge of valuing ecosystem services that have no material benefits. Global Environmental Change 44:57-67. https://doi.org/10.1016/j. gloenvcha.2017.03.005

Solow, R. M. 1985. Economic history and economics. American Economic Review 75(2):328-331.

Spangenberg, J. H., and J. Settele. 2010. Precisely incorrect? Monetising the value of ecosystem services. Ecological Complexity 7(3):327-337. https://doi.org/10.1016/j.ecocom.2010.04.007

Spash, C. L. 2007. Deliberative monetary valuation (DMV): issues in combining economic and political processes to value environmental change. Ecological Economics 63(4):690-699. https://doi.org/10.1016/j.ecolecon.2007.02.014

Spash, C. L. 2008. Deliberative monetary valuation and the evidence for a new value theory. Land Economics 84(3):469-488. https://doi.org/10.3368/le.84.3.469

Stammler, F., and V. Peskov. 2008. Building a 'culture of dialogue' among stakeholders in North-West Russian oil extraction. Europe-Asia Studies 60(5):831-849. https://doi.org/10.1080/0966$\underline{8130802085182}$

Star, S. L., and J. R. Griesemer. 1989. Institutional ecology, 'translations' and boundary objects: amateurs and professionals in Berkeley's Museum of Vertebrate Zoology, 1907-39. Social Studies of Science 19(3):387-420. https://doi.org/10.1177/03063$\underline{1289019003001}$ 
Tengberg, A., S. Fredholm, I. Eliasson, I. Knez, K. Saltzman, and O. Wetterberg. 2012. Cultural ecosystem services provided by landscapes: assessment of heritage values and identity. Ecosystem Services 2:14-26. https://doi.org/10.1016/j.ecoser.2012.07.006

Usher, L. E., and E. Gómez. 2016. Surf localism in Costa Rica: exploring territoriality among Costa Rican and foreign resident surfers. Journal of Sport \& Tourism 20(3-4):195-216. https://doi. org/10.4324/9781351213707-3

van Noorloos, F. 2011. Residential tourism causing land privatization and alienation: new pressures on Costa Rica's coasts. Development 54(1):85-90. https://doi.org/10.1057/dev.2010.90

Wang, C., and M. A. Burris. 1997. Photovoice: concept, methodology, and use for participatory needs assessment. Health Education \& Behavior 24(3):369-387. https://doi. org/10.1177/109019819702400309

Wegner, G., and U. Pascual. 2011. Cost-benefit analysis in the context of ecosystem services for human well-being: a multidisciplinary critique. Global Environmental Change 21 (2):492-504. https://doi.org/10.1016/j.gloenvcha.2010.12.008

West, P., J. Igoe, and D. Brockington. 2006. Parks and peoples: the social impact of protected areas. Annual Review of Anthropology 35(1):251-277. https://doi.org/10.1146/annurev. anthro.35.081705.123308

Zúñiga, X. 2003. Bridging differences through dialogue. About Campus 7(6):8-16. https://doi.org/10.1177/108648220300700603 